\title{
A recycling culture of Neochloris oleoabundans in a bicarbonate-based integrated carbon capture and algae production system with harvesting by auto-flocculation
}

\author{
Chenba Zhu, Ruolan Zhang, Longyan Cheng and Zhanyou Chi
}

\begin{abstract}
Background: A bicarbonate-based integrated carbon capture and algae production system (BICCAPS) uses carbonate to capture $\mathrm{CO}_{2}$ and produce bicarbonate for alkalihalophilic microalgal cultivation. In this process, carbonate is regenerated and re-used for $\mathrm{CO}_{2}$ capture. However, a practical example of a recycling culture to prove its feasibility is still absent.

Results: To reach this goal, a recycling culture of Neochloris oleoabundans was created in this study. The effect of bicarbonate concentration on $N$. oleoabundans growth showed that the highest productivity was obtained at $0.3 \mathrm{~mol} \mathrm{~L}^{-1}$, but the highest apparent carbon utilization efficiency was obtained at $0.1 \mathrm{~mol} \mathrm{~L}^{-1}$. The harvest of algal biomass was tested with alkaline flocculation, which is induced by high $\mathrm{pH}$ due to bicarbonate consumption. The result showed that the maximum recovery rate of $97.7 \pm 0.29 \%$ was reached with a supplement of $20 \mathrm{mM} \mathrm{Ca}{ }^{2+}$. Compared with this, alkaline flocculation without $\mathrm{Ca}^{2+}$ also resulted in a high recovery rate of up to $97.4 \pm 0.21 \%$ in culture with 0.7 mol L ${ }^{-1}$ bicarbonate. In recycling culture, the spent medium was bubbled with $\mathrm{CO}_{2}$ and re-used for algal culture. After eight times of recycling, biomass productivity in recycling culture with 0.1 and $0.3 \mathrm{~mol} \mathrm{~L}^{-1}$ bicarbonate was 0.24 and $0.39 \mathrm{~g} \mathrm{~L}^{-1}$ day ${ }^{-1}$, respectively, higher than the 0.20 and $0.30 \mathrm{~g} \mathrm{~L}^{-1}$ day $^{-1}$ in the control. The apparent carbon utilization efficiencies achieved in these semi-continuous cultures with $0.1 \mathrm{~mol} \mathrm{~L}^{-1}$ bicarbonate were $242 \pm 3.1$ and $266 \pm 11 \%$ for recycling and control culture, respectively, while those with $0.3 \mathrm{~mol} \mathrm{~L}^{-1}$ bicarbonate were $98 \pm 0.78$ and $87 \pm 3.6 \%$, respectively.
\end{abstract}

Conclusions: This study proved the feasibility of BICCAPS recycling culture with the first practical example. More importantly, the produced algal biomass can be harvested without any flocculant supplement. Thus, this process can reduce both culturing and harvesting costs in algal biomass production.

Keywords: Bicarbonate, Flocculation, Recycling culture, Neochloris oleoabundans

\section{Background}

Worldwide $\mathrm{CO}_{2}$ emissions have increased the annual average concentration in the atmosphere to $400 \mathrm{ppm}$ [1], and this has resulted in a series of problems, including global warming and ocean acidification. This situation may be mitigated by replacing fossil fuels with renewable

*Correspondence: chizhy@dlut.edu.cn

School of Life Science and Biotechnology, Dalian University of Technology, Dalian, China energy or recycling utilization of $\mathrm{CO}_{2}$ [2]. Microalgae are promising to contribute to both of these two approaches by converting $\mathrm{CO}_{2}$ into biofuel [3]. However, commercial production of microalgal biomass is still limited by high costs $[4,5]$. A process named bicarbonate-based integrated carbon capture and algae production system (BICCAPS) was proposed to reduce algal biomass production cost [6]. In this system, bicarbonate generated from $\mathrm{CO}_{2}$ absorption by carbonate is used to culture alkalihalophilic microalgae to avoid the high cost of $\mathrm{CO}_{2}$ 
purification and transportation. At the same time, it uses carbonate regenerated from algal culture to absorb $\mathrm{CO}_{2}$ and to reduce the high cost of carbonate regeneration with traditional methods [6]. Thus, BICCAPS is promising to simultaneously reduce the cost of carbon capture and microalgal culture.

To test the feasibility of BICCAPS, alkalihalophilic cyanobacterium Euhalothece sp. was cultured with $1.0 \mathrm{M}$ sodium bicarbonate. This culture resulted in an algal biomass productivity of up to $1.2 \mathrm{~g} \mathrm{~L}^{-1} \mathrm{day}^{-1}$, indicating that high productivity is achievable at this extreme condition [7]. This high concentration of bicarbonate can supply sufficient carbon at the beginning of each culture, with no continuous $\mathrm{CO}_{2}$ bubbling or interval feeding necessary. This allows the use of a photobioreactor with a simple structure. A low-cost horizontal floating photobioreactor without gas bubbling and/or an agitation system that uses waves as the only energy for mixing was developed in our previous study [8]. This progress systematically reduced the cost of photobioreactor manufacturing, carbon supply, energy consumption, and culture condition control ( $\mathrm{pH}, \mathrm{DO}$, temperature) [8] and showed great potential to reduce microalgal biomass production cost. However, recycling the culture is obligatory for a BICCAPS, since sodium bicarbonate has a price of approximately $\$ 200$ ton $^{-1}$, and it would be more expensive than using $\mathrm{CO}_{2}$ as feedstock if not recycled. Thus, the feasibility of using spent medium enriched with carbonate to absorb $\mathrm{CO}_{2}$ and conducting culture recycling must be proven by experiment.

In addition to cultivation, the harvesting of algal biomass is a significant cost and accounts for approximately $20-30 \%$ of total production cost [9]. Flocculation is promising to reduce this cost, but it is usually induced by a flocculant supplement [10]. This is not only expensive but also causes the potential problem of biomass contamination [11]. To address these problems, alkaline flocculation (auto-flocculation) was proposed as a simple method [12]. It is induced by a high $\mathrm{pH}$ and the precipitation of calcite (calcium carbonate) or brucite (magnesium hydroxide) [13]. However, flocculation induced by calcite is not stable. Studies have shown that although high flocculation efficiency was achieved with $12.5 \mathrm{mM}$ calcium concentration [13], extensive $\mathrm{CaCO}_{3}$ precipitation yielded only partial flocculation in another study [14]. Different from this, magnesium hydroxide-induced flocculation worked well in a high $\mathrm{pH}$ range of 10-11 [15]. However, this requires a large amount of alkaline to increase the $\mathrm{pH}$ and it is very expensive [11].

In a BICCAPS, consumption of $\mathrm{HCO}_{3}{ }^{-}$leads to an increased $\mathrm{pH}$ and a higher ratio of $\mathrm{CO}_{3}{ }^{2-} / \mathrm{HCO}_{3}{ }^{-}$[16]. This may be used to induce auto-flocculation by adding low concentrations of calcium, or ideally, without any flocculant supplement (Fig. 1). Thus, auto-flocculation was tested in the harvesting of algal biomass in this study. Neochloris oleoabundans was selected for this test, since it is tolerant to high concentrations of bicarbonate [17] and its biomass is enriched with lipid for biofuel production $[18,19]$. However, only alkalihalophilic microalgae are suitable for BICCAPS. Thus, selection of alkalihalophilic strains is very important. It was reported that some microalgal strains in soda lake evolved to be tolerant to saturated bicarbonate [20]. Thus, an adaption process was conducted to improve algal strains' tolerant capability to high concentration of bicarbonate at first, and this was achieved by gradually increasing bicarbonate concentration contained in the medium. Culture recycling of $N$. oleoabundans was conducted with a semi-continuous mode, in which spent medium was used to absorb $\mathrm{CO}_{2}$ and then re-used in cultivation. The results reported here proved the feasibility of BICCAPS culture recycling with a practical example.

\section{Methods \\ Microalgal strain and culture medium}

The microalgal strain $N$. oleoabundans UTEX1185 was purchased from the Culture Collection of Texas University (USA). It was cultivated in medium that contained $\mathrm{NaHCO}_{3}, 25.2 \mathrm{~g} \mathrm{~L}^{-1} ; \mathrm{NaNO}_{3}, 0.5 \mathrm{~g} \mathrm{~L}^{-1} ; \mathrm{NaCl}$, $0.025 \mathrm{~g} \mathrm{~L}^{-1} ; \mathrm{MgSO}_{4}, 0.05 \mathrm{~g} \mathrm{~L}^{-1} ; \mathrm{KH}_{2} \mathrm{PO}_{4}, 0.322 \mathrm{~g} \mathrm{~L}^{-1}$; $\mathrm{CaCl}_{2}, 0.02 \mathrm{~g} \mathrm{~L}^{-1} ; \mathrm{FeCl}_{3} \cdot 6 \mathrm{H}_{2} \mathrm{O}, 0.005 \mathrm{~g} \mathrm{~L}^{-1}$; and A5 trace elemental solution $1 \mathrm{~mL} \mathrm{~L}^{-1}$ [17]. However, at first, the algae could not grow well in culture medium containing $0.3 \mathrm{~mol} \mathrm{~L}^{-1}$ bicarbonate, although it was reported that this algae can tolerate $0.3 \mathrm{~mol} \mathrm{~L}^{-1}$ bicarbonate [17]. Thus, the algae were first cultured with $0.08 \mathrm{~mol} \mathrm{~L}^{-1}$ bicarbonate, and then, the concentration was increased by $0.02 \mathrm{~mol} \mathrm{~L}^{-1}$ every 4 days until it reached $0.3 \mathrm{~mol} \mathrm{~L}^{-1}$. This culture was conducted in a 1-L Erlenmeyer flask with a work volume of $0.4 \mathrm{~L}$, and it was bubbled with air at a

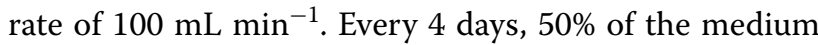
was replaced with fresh medium containing $0.08 \mathrm{~mol} \mathrm{~L}^{-1}$ bicarbonate. This process lasted for 6 months, and the obtained algal strain adapted to a $\mathrm{NaHCO}_{3}$ concentration of $25.2 \mathrm{~g} \mathrm{~L}^{-1}$, or $0.3 \mathrm{M}$.

\section{Algal cultivation and biomass concentration measurement}

To test the effect of bicarbonate concentration on growth of the adapted $N$. oleoabundans strain, batch cultures for 5 days were conducted with bicarbonate at concentrations of $0.1,0.3,0.5$, and $0.7 \mathrm{~mol} \mathrm{~L}^{-1}$. Another culture was set up with a zero bicarbonate concentration that contained $0.3 \mathrm{~mol} \mathrm{~L}^{-1}$ sodium chloride. Both of these were conducted in a 1-L Erlenmeyer flask with a work volume of $0.4 \mathrm{~L}$. To test the recyclability of spent 


\section{Capturing $\mathrm{CO}_{2}$ with alkaline supernatant}

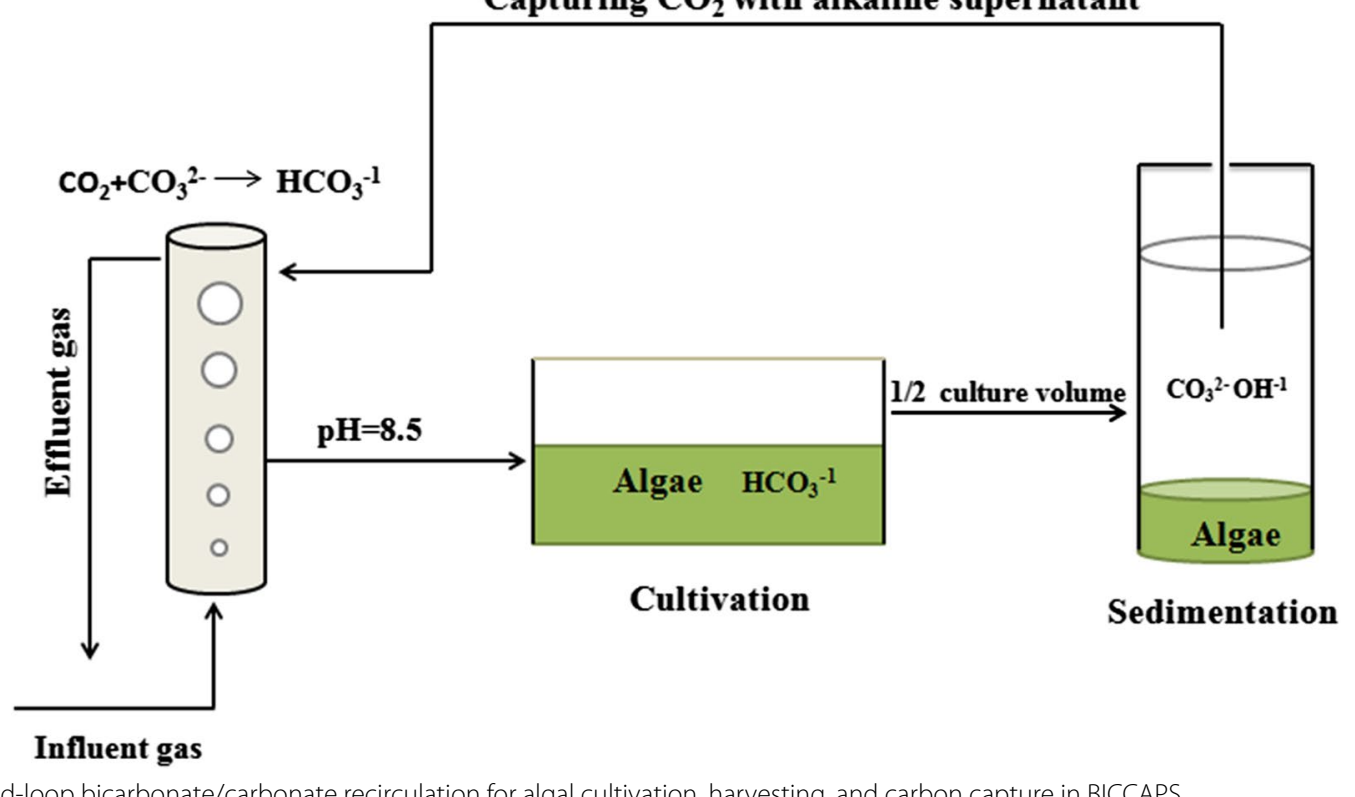

Fig. 1 Closed-loop bicarbonate/carbonate recirculation for algal cultivation, harvesting, and carbon capture in BICCAPS

medium, cultures grown in 3.0-L Erlenmeyer flasks were conducted in semi-continuous mode (Fig. 2) with an initial culture volume of $0.8 \mathrm{~L}$. After 2 days, $50 \%$ of the culture was removed, and the same volume of fresh medium was added to re-start the culture. The removed cell suspension was then centrifuged, followed by bubbling with pure $\mathrm{CO}_{2}$ for $\mathrm{pH}$ adjustment and carbon replenishment, which usually takes approximately $20 \mathrm{~min}$. When the $\mathrm{pH}$ of this medium decreased to 8.50 , which is the same
$\mathrm{pH}$ as fresh medium, the bubbling was stopped, and the supernatant was filtered through $0.22-\mu \mathrm{m}$ hydrophilic membranes, and stored at $4{ }^{\circ} \mathrm{C}$ in the refrigerator. After $48 \mathrm{~h}$, when the culture was finished, this $\mathrm{CO}_{2}$-replenished medium was used to replace $50 \%$ of the culture in the flask. The removed culture was then treated as such again. To avoid nutrient depletion, the same amounts of nutrients as in fresh medium were replenished in the recycled medium on the 8 th and 14th day. To make a

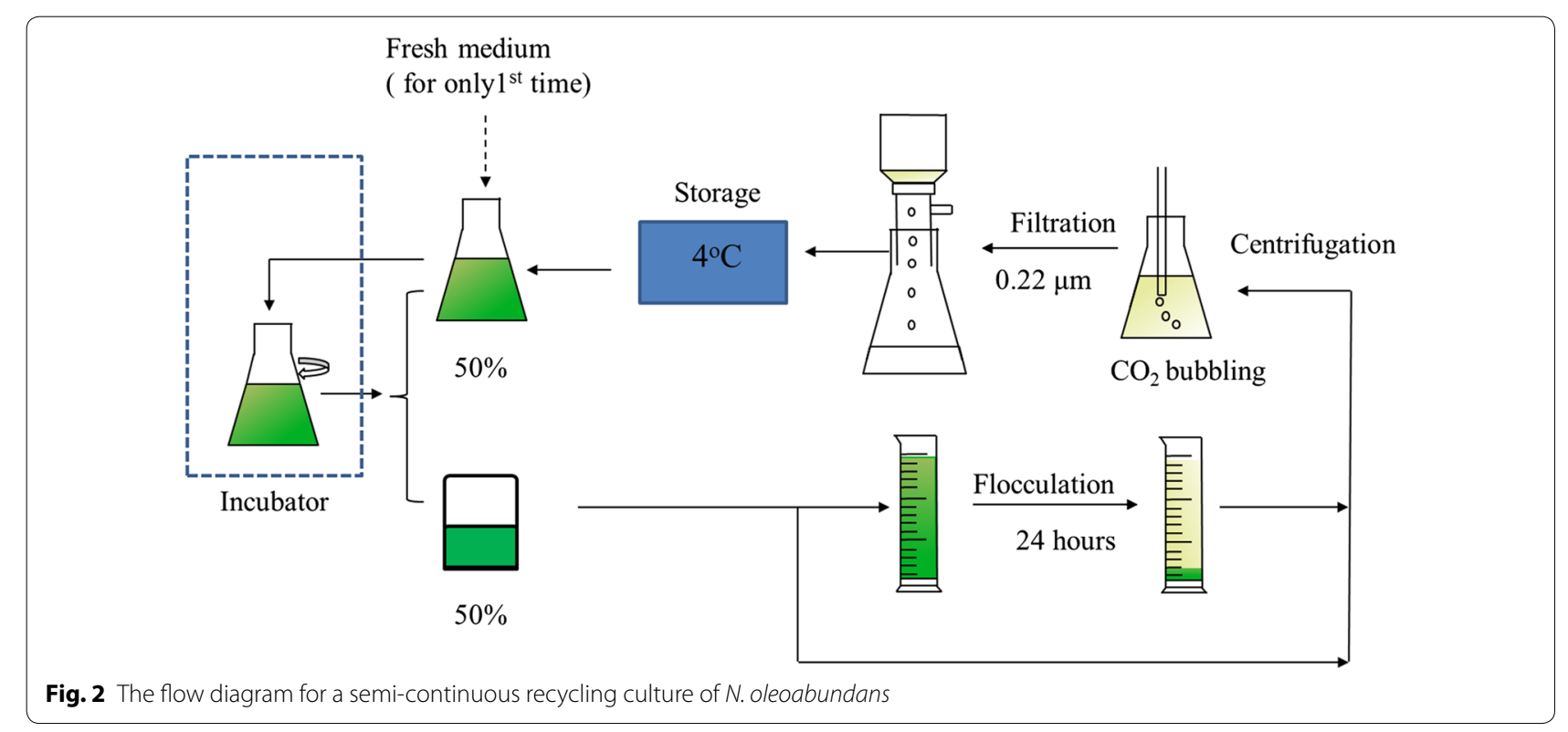


comparison, a group that always used fresh medium to replace $50 \%$ of the culture in the flask every 2 days was used. The cultures were continuously illuminated at $141.5 \mu \mathrm{mol} \mathrm{m} \mathrm{m}^{-2} \mathrm{~s}^{-1}$. The flasks were orbital shaken at $140 \mathrm{rpm}$ at a temperature of $25^{\circ} \mathrm{C}$ with no air bubbling. Biomass productivity $\left(P_{\text {Biomass }}\right)$ and specific growth rate $(\mu)$ were calculated as

$$
\begin{aligned}
& P_{\text {Biomass }}\left(\mathrm{g} \mathrm{L}^{-1} \mathrm{day}^{-1}\right)=\frac{\mathrm{DCW}_{2}-\mathrm{DCW}_{1}}{t_{2}-t_{1}}, \\
& \mu\left(\mathrm{day}^{-1}\right)=\frac{\ln \left(\mathrm{DCW}_{2} / \mathrm{DCW}_{1}\right)}{t_{2}-t_{1}},
\end{aligned}
$$

where $P_{\text {Biomass }}$ is biomass productivity $\left(\mathrm{g} \mathrm{L}^{-1}\right.$ day $^{-1}$ ), $\mu$ is the specific growth rate $\left(\right.$ day $\left.^{-1}\right)$, and $\mathrm{DCW}_{2}$ and $\mathrm{DCW}_{1}$ are the dry cell weight (DCW) at time $t_{2}$ and $t_{1}$, respectively.

DCW was determined according to Zhu et al. [21]. Briefly, triplicates of $40 \mathrm{~mL}$ samples were acidified with hydrochloric acid and then centrifuged at 10,000 rpm for $5 \mathrm{~min}$ at $25^{\circ} \mathrm{C}$. The algal pellets were then washed twice with a $40 \mathrm{~mL}$ ammonium bicarbonate solution. Finally, the pellets were re-suspended in $2 \mathrm{~mL}$ of ammonium bicarbonate, and this suspension was dried overnight at $105{ }^{\circ} \mathrm{C}$ until a constant weight. DCW was calculated by subtracting the empty dish weight from total weight.

\section{Calculation of apparent carbon utilization efficiency (\%)}

As the consumed carbon could be from both of initial medium or air, the carbon utilization efficiency in this study is defined as "apparent carbon utilization efficiency", and it was calculated as follows:

$$
\operatorname{Efficiency}(\%)=\frac{\Delta \mathrm{DCW} \times C_{\mathrm{C}}}{\Delta \mathrm{Tic}} \times \%,
$$

where the $\Delta$ Tic is the variation of Tic during the cultivation process and $\triangle \mathrm{DCW}$ represents the variation in biomass concentration. $C_{\mathrm{C}}$ represents the carbon content in the dry cell weight of the algal biomass, which was measured with a combustion CHNS-analyzer (Element, Germany). In this study, the $C_{\mathrm{C}}$ of $45.7 \pm 0.18,51.6 \pm 0.17$, $54.7 \pm 0.14$ and $53.1 \pm 0.01 \%$ was achieved in algal biomasses cultured with bicarbonate concentrations of 0.1 , $0.3,0.5$, and $0.7 \mathrm{~mol} \mathrm{~L}^{-1}$, respectively. To simplify the calculation process, it was assumed that the $C_{\mathrm{C}}$ did not change during the whole cultivation process or in different culture modes when using a constant bicarbonate concentration.
Since the alkalinity of the culture media does not change with $\mathrm{CO}_{2}$ consumption or supply [22], total inorganic carbon (Tic) was calculated with the measured $\mathrm{pH}$ according to the following equation [23].

$$
\text { Tic }=\frac{\text { Alc }}{\alpha_{1}+2 \alpha_{2}}
$$

where Alc is the medium alkalinity and $\alpha_{1}$ and $\alpha_{2}$ are the ionization fractions of $\mathrm{HCO}_{3}^{-1}$ and $\mathrm{CO}_{3}{ }^{2-}$, respectively, which are obtained as a function of $\mathrm{pH}$ and the equilibrium constants $k_{1}$ and $k_{2}$ as shown in the following equations.

$$
\begin{aligned}
& \alpha_{1}=\frac{1}{\left(1+\frac{H^{+}}{k_{1}}+\frac{k_{2}}{H^{+}}\right)}, \\
& \alpha_{2}=\frac{1}{\left(1+\frac{H^{+}}{k_{2}}+\frac{\left(H^{+}\right)^{2}}{k_{1} k_{2}}\right)} .
\end{aligned}
$$

The equilibrium constants $k_{1}$ and $k_{2}$ were theoretically calculated from salinity and temperature according to Millero et al. [24].

In addition, the concentration of dissolved $\mathrm{CO}_{2}$ $\left(\mathrm{CO}_{2 \mathrm{D}}\right)$ was calculated from the measured $\mathrm{pH}$ value and Tic as follows:

$$
\mathrm{CO}_{2 \mathrm{D}}=\operatorname{Tic} \times \frac{1}{\left(1+\frac{k_{1}}{H^{+}}+\frac{k_{1} k_{2}}{\left(H^{+}\right)^{2}}\right)} .
$$

In this study, the $\mathrm{CO}_{2 \mathrm{D}}{ }^{*}$ is the liquid-phase $\mathrm{CO}_{2 \mathrm{D}}$ concentration, which is in equilibrium with the air $\mathrm{CO}_{2}$, and the corresponding culture $\mathrm{pH}$ was defined as $\mathrm{pH}^{*}$. This equation was solved using Matlab 14.0.

The $\mathrm{CO}_{2}{ }^{*}$ can be calculated as follows:

$$
\mathrm{CO}_{2}^{*}=\mathrm{H}_{\mathrm{CO}_{2}} P_{\mathrm{CO}_{2}} \text {, }
$$

where $P_{\mathrm{CO} 2}$ is the partial pressure of saturated $\mathrm{CO}_{2}$ in the atmosphere and $\mathrm{H}_{\mathrm{CO} 2}$ is the Henry's constant for $\mathrm{CO}_{2}$.

\section{Alkaline flocculation and measurements of recovery efficiency (RE)}

Algal sedimentation was first investigated with fresh medium re-suspended algal cells, as this can well control culture conditions, such as $\mathrm{pH}$ and biomass concentration. To test this, algal cells were harvested by centrifugation and then re-suspended in fresh medium. This pretreatment has no significant influence on 
flocculation $[25,26]$. To study the influence of calcium concentration on flocculation, the re-suspended algal suspension was added with different concentrations of calcium and stirred intensively at $1000 \mathrm{rpm}$ for $10 \mathrm{~min}$, followed by a gentle mixing of $250 \mathrm{rpm}$ for another $20 \mathrm{~min}$. The prepared algal suspension was subsequently allowed to settle for $60 \mathrm{~min}$. In addition, the effect of biomass concentration on auto-flocculation was tested, where the re-suspended cell suspension had no pretreatment and was allowed to settle from 0.5 to $24 \mathrm{~h}$. These experiments were carried out in triplicates in 50-mL graduated cylinders with a work volume of $40 \mathrm{~mL}$. The biomass concentration and $\mathrm{pH}$ were $0.5 \mathrm{~g} \mathrm{~L}^{-1}$ and 10.0, respectively.

To test the repeatability of auto-flocculation in spent medium, the recovery efficiency of culture in spent medium was tested with the medium-microalgal cell mixture drawn from bath and semi-continuous mode. Neither of these cultures had any treatment. For batch culture, the cell suspension was drawn after 5 days of batch cultivation, while the recycling semi-continuous culture was drawn per 2 days. To avoid the culture loss of recycling culture, the spent medium in the semi-continuous culture was collected after the flocculation test. However, in our practical experiment, $2 \mathrm{~mL}$ of medium was used for sampling, and the rest was recovered by centrifugation, to avoid volume loss. The recovery efficiency was measured by calculating the absorbance difference between the initial $\left(C_{0}\right)$ and the final $\left(C_{\mathrm{t}}\right)$ optical density at $750 \mathrm{~nm}$.

The recovery efficiency (RE) was calculated as:

$$
\text { Recovery efficiency }(\%)=\frac{C_{0}-C_{t}}{C_{0}} \times 100,
$$

where $C_{0}$ is the initial optical density and $C_{\mathrm{t}}$ is the final optical density after settlement.

The concentrating factor $(\mathrm{CF})$ was determined as

$$
\mathrm{CF}=\frac{H_{1}}{H_{2}},
$$

where $H_{1}$ is the height of algal suspension in the cylinder at the beginning and $\mathrm{H}_{2}$ is the height of algal sludge at the end of sedimentation.

\section{Statistical analysis}

Differences between groups were performed by one-way analysis of variance (ANOVA) tests. The significant differences were considered at $p<0.05$, as determined by SigmaStat (version 3.1) software (SPSS).

\section{Results}

Effect of bicarbonate concentration on the growth of $N$. oleoabundans

Biomass concentration and $\mathrm{pH}$ were measured during 5 days of cultivation with different concentrations of sodium bicarbonate. As shown in Fig. 3a, the algal growth with zero bicarbonate was low after 5 days of cultivation, where its final biomass density was only $0.083 \mathrm{~g} \mathrm{~L}^{-1}$. This is because the algal growth was limited due to low carbon concentrations. Compared with this, the bicarbonate can provide sufficient inorganic carbon for algal growth, and high biomass concentrations of $0.94 \pm 0.02,1.64 \pm 0.03,1.50 \pm 0.05$ and $1.52 \pm 0.02 \mathrm{~g} \mathrm{~L}^{-1}$ were achieved in cultures with $0.1,0.3$, 0.5 , and $0.7 \mathrm{~mol} \mathrm{~L}^{-1}$ of bicarbonate, respectively. The corresponding average volumes of productivity during the first 4 days were $0.21 \pm 0.01,0.40 \pm 0.01,0.36 \pm 0.01$ and $0.29 \pm 0.01 \mathrm{~g} \mathrm{~L}^{-1} \mathrm{day}^{-1}$, respectively, while the specific growth rates were $1.71 \pm 0.03,1.70 \pm 0.03,1.17 \pm 0.04$,

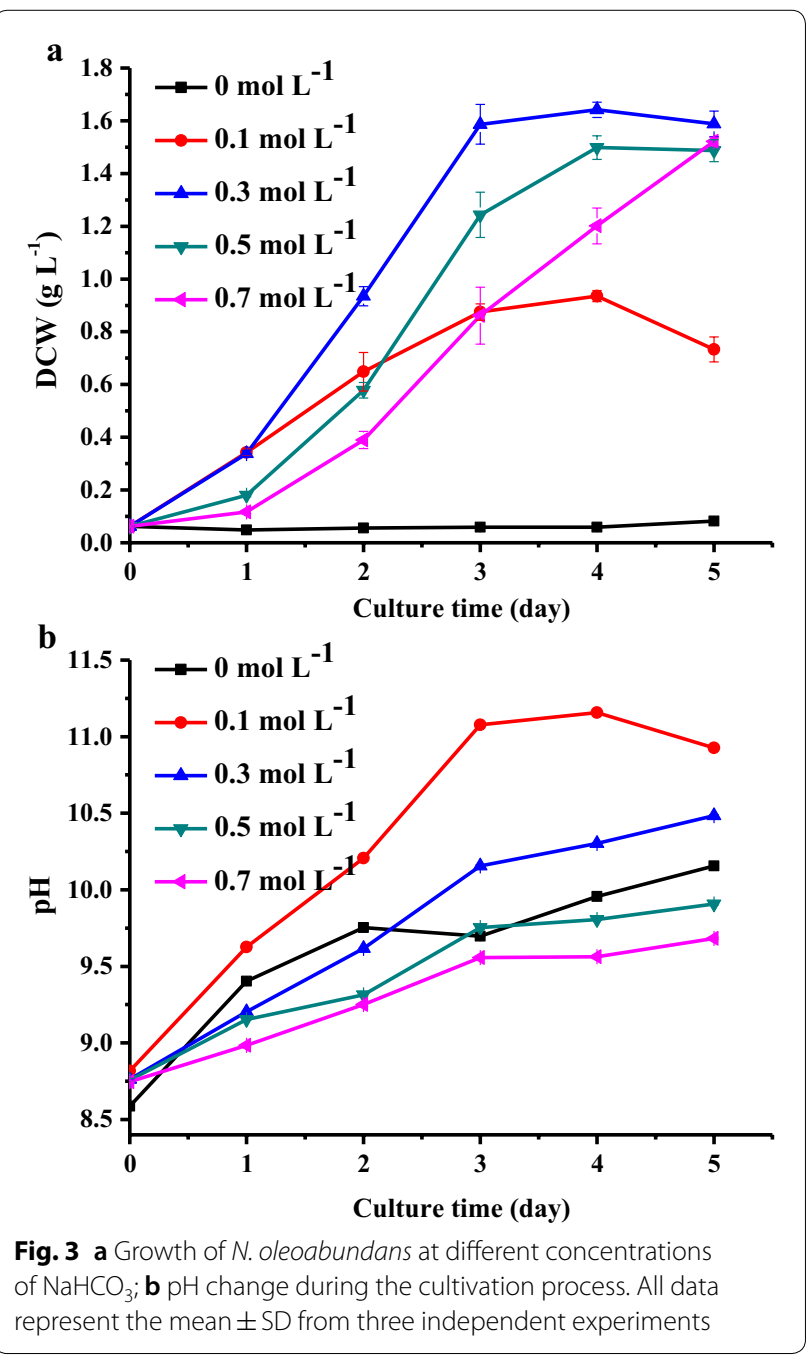


and $1.21 \pm 0.07$ day $^{-1}$, respectively. This indicates that $N$. oleoabundans can survive in bicarbonate concentrations up to $0.7 \mathrm{~mol} \mathrm{~L}^{-1}$, although it had optimal growth at $0.3 \mathrm{~mol} \mathrm{~L}^{-1}$.

Since algal growth is usually affected by $\mathrm{pH}$, changes in $\mathrm{pH}$ during the culture process were measured. As shown in Fig. 3a, biomass concentration in the culture with $0.1 \mathrm{~mol} \mathrm{~L}^{-1}$ bicarbonate stopped increasing after 3 days and decreased at day 5 . This should be caused by high $\mathrm{pH}$ limiting, as the $\mathrm{pH}$ of the $0.1 \mathrm{~mol} \mathrm{~L}^{-1}$ culture was higher than 11.2 at day 3 (Fig. 3b). For the other three groups, $\mathrm{pH}$ values were always less than 10.5 , indicating that higher concentrations of bicarbonate/carbonate had better $\mathrm{pH}$ buffer effects [27].

\section{Effect of bicarbonate concentration on carbon utilization efficiency}

Bicarbonate concentration significantly affected carbon utilization efficiency. As shown in Fig. 4, the apparent carbon utilization efficiency decreased with increases in bicarbonate concentration, and the overall carbon utilization efficiencies of $86.6 \pm 1.5,63 \pm 1.0,42.5 \pm 1.1$ and $39.4 \pm 1.9 \%$ were achieved in cultures with bicarbonate concentrations of $0.1,0.3,0.5$, and $0.7 \mathrm{~mol} \mathrm{~L}^{-1}$, respectively. $\mathrm{pH}^{*}$ is the culture $\mathrm{pH}$ when the dissolved $\mathrm{CO}_{2}$ in the culture is equal to the saturated concentration of $\mathrm{CO}_{2}$ in the medium. This can be calculated through Eq. 7, and it was calculated as 9.45, 9.64, 9.86 and 10.11 for bicarbonate concentrations of $0.1,0.3,0.5$, and $0.7 \mathrm{~mol} \mathrm{~L}^{-1}$, respectively. $\mathrm{CO}_{2}$ is transferred to the medium from the air when its $\mathrm{pH}$ exceeds $\mathrm{pH}^{*}$. This is the reason why higher apparent carbon utilization efficiency was achieved in the culture with $0.1 \mathrm{~mol} \mathrm{~L}^{-1}$, since its $\mathrm{pH}$ exceeded $\mathrm{pH}^{*}$ after the 1st day (Fig. 3b).

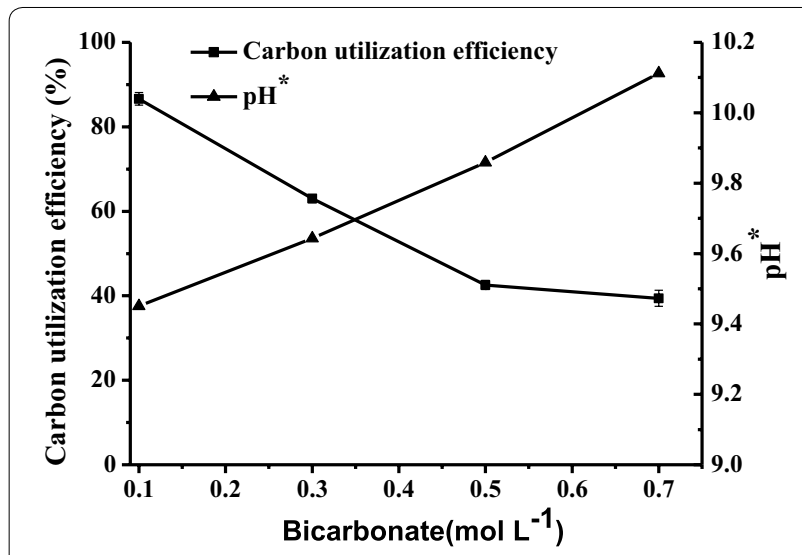

Fig. 4 The effect of bicarbonate concentration on carbon utilization efficiency and $\mathrm{pH}^{*}$

\section{Alkaline flocculation with or without calcium}

Figure 5 shows the harvesting efficiency with flocculation by supplement of different concentrations of calcium. On the whole, higher concentrations of calcium resulted in higher recovery efficiency. The highest was $97.7 \pm 0.29 \%$, achieved at a calcium concentration of $20 \mathrm{mmol} \mathrm{L}^{-1}$. Different from this, the concentrating factor decreased with increased dosages of calcium. The highest was $97.0 \pm 5.25$, achieved at a calcium concentration of $5 \mathrm{mmol} \mathrm{L}{ }^{-1}$. A high concentration of calcium produced loose calcium carbonate precipitation, which increased the height of the algal sludge. This should be the reason why a higher calcium concentration resulted in a lower concentrating factor. A similar phenomenon was observed in another study on algal flocculation induced by magnesium [26].

For auto-flocculation without any calcium supplement, the recovery efficiency with initial biomass concentrations of $0.5,1.0$ and $2.0 \mathrm{~g} \mathrm{~L}^{-1}$ was investigated. As shown in Fig. 6a, recovery efficiency was less than 50\% for all three concentrations in the first two hours. After $24 \mathrm{~h}$, the recovery efficiency was $92.5 \pm 0.62,85.3 \pm 0.01$ and $92.3 \pm 0.17 \%$ for biomass concentrations of $0.5,1.0$ and $2.0 \mathrm{~g} \mathrm{~L}^{-1}$, respectively. This indicates that auto-flocculation is an effective harvesting method for N. oleoabundans. However, there was no significant difference between recovery efficiencies with these three investigated biomass concentrations.

\section{Effect of bicarbonate concentration to auto-flocculation efficiency}

In addition to affecting algal growth, bicarbonate concentration also influences the efficiency of auto-flocculation.

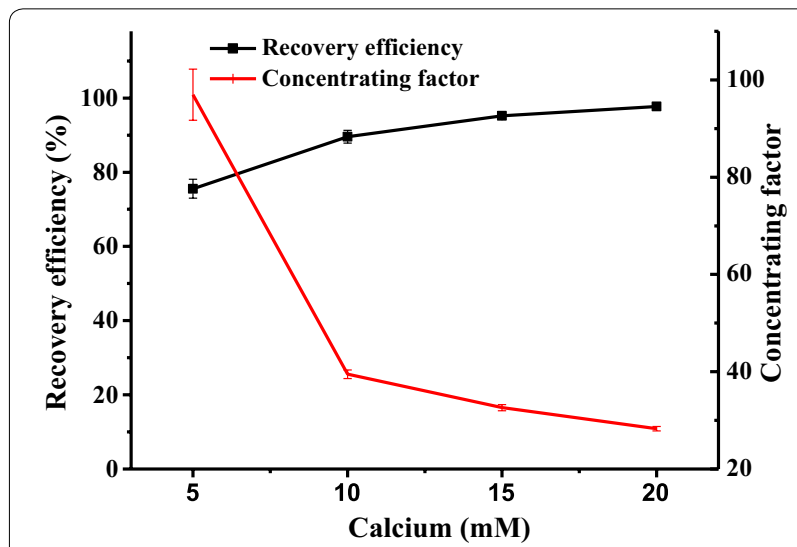

Fig. 5 The flocculation efficiency of $N$. oleoabundans and concentrating factor at different calcium concentrations ( $N$. oleoabundans biomass concentration: $0.5 \mathrm{~g} \mathrm{~L}^{-1} ; \mathrm{pH}$ : 10.0, settling time: $1 \mathrm{~h}$ ). All data represent the mean \pm SD from three independent experiments 


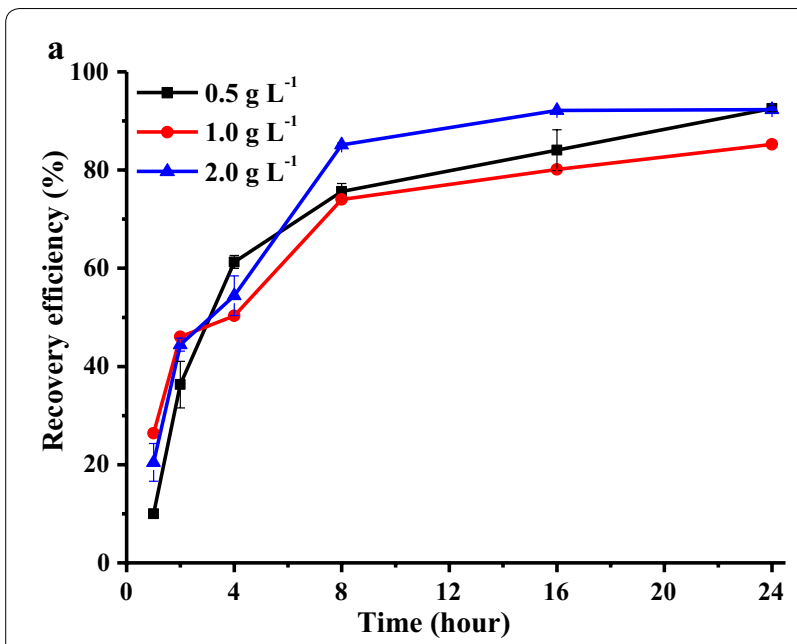

b

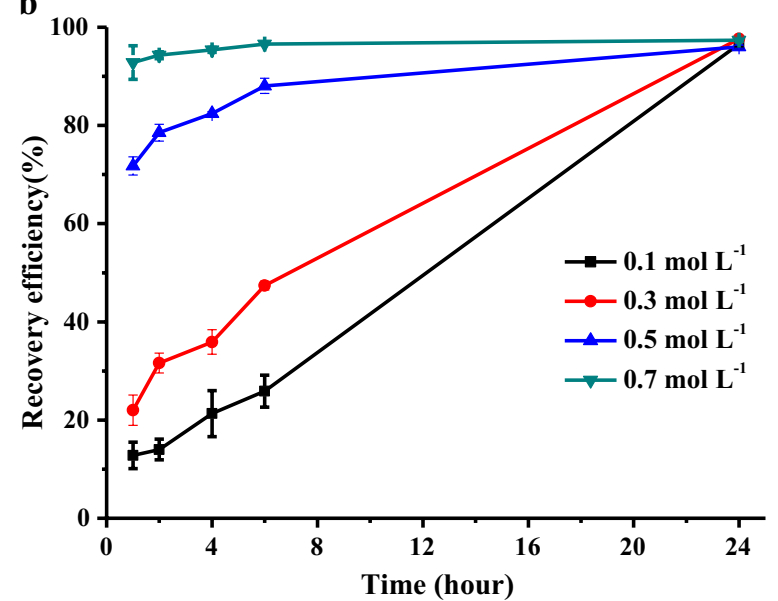

Fig. 6 The flocculation efficiency of N. oleoabundans without added $\mathrm{Ca}^{2+}$. a Efficiency of auto-flocculation versus time with different biomass concentration (bicarbonate concentration: $0.3 \mathrm{~mol} \mathrm{~L}^{-1}$, and $\mathrm{pH}: 10.0$ ), $\mathbf{b}$ flocculation in spent medium from 5 days batch cultivation with different bicarbonate concentration. All data represent the mean $\pm \mathrm{SD}$ from three independent experiments

As shown in Fig. 6b, recovery efficiency was improved with increased bicarbonate concentration in the first hour, and the highest was $92.8 \pm 3.4 \%$, achieved at $0.7 \mathrm{~mol} \mathrm{~L}^{-1}$. However, there was no difference in recovery efficiency for these four cultures in $24 \mathrm{~h}$, where the recovery efficiencies were $96.6 \pm 0.67,97.6 \pm 0.39,96.0 \pm 0.31$ and $97.4 \pm 0.21 \%$ for $0.1,0.3,0.5$, and $0.7 \mathrm{~mol} \mathrm{~L}^{-1}$, respectively.

\section{Recycling culture}

As shown in Fig. 7a, there was no significant difference in biomass concentration between fresh and recycled medium during the first 4 days for $0.3 \mathrm{~mol} \mathrm{~L}^{-1}$ bicarbonate and the first 6 days for $0.1 \mathrm{~mol} \mathrm{~L}^{-1}$. However, biomass concentration in the recycling culture with $0.3 \mathrm{~mol} \mathrm{~L}^{-1}$ bicarbonate was lower than its control from the 4th to 16th day. This also occurred from the 6th to 8th day for the culture with $0.1 \mathrm{~mol} \mathrm{~L}^{-1}$ bicarbonate, which should be attributed to nutrient depletion, since nutrient supplements added at the 8th and 14th day in the recycled medium increased the biomass productivity of the $0.3 \mathrm{~mol} \mathrm{~L}^{-1}$ recycling culture (Fig. $8 \mathrm{~b}$ ), while that of $0.1 \mathrm{~mol} \mathrm{~L}^{-1}$ recycling culture was at the 8th and 18th day. However, a small decrease in biomass productivity was found in $0.1 \mathrm{~mol} \mathrm{~L}^{-1}$ recycling culture at 14th day, and this reason was not clear, but both of two recycling cultures produced even higher biomass concentration than control at 18th day (Fig. 7a). This proved the feasibility of BICCAPS recycling culture.

The $\mathrm{pH}$ change during the entire recycling culture was recorded. As shown in Fig. 7b, the $\mathrm{pH}$ at harvesting time was from 9.96 to 10.76 in recycling culture with $0.1 \mathrm{~mol} \mathrm{~L}^{-1}$, and that of fresh medium was from 9.97 to 11.20 . Compared with this, a stable $\mathrm{pH}$ range was found in cultures with $0.3 \mathrm{~mol} \mathrm{~L}^{-1}$ bicarbonate due to a stronger buffering effect. Its $\mathrm{pH}$ in the recycling culture was from 9.35 to 9.86, and that of the control was from 9.34 to 10.12 . This showed that the $\mathrm{pH}$ was maintained in a stable range by replacing culture medium with recycled medium after $\mathrm{CO}_{2}$ absorption.

The recovery efficiency of $0.1 \mathrm{~mol} \mathrm{~L}^{-1}$ recycling culture was from $80.4 \pm 0.1$ to $96.1 \pm 0.4 \%$, and that of $0.3 \mathrm{~mol} \mathrm{~L}^{-1}$ recycling culture was $84.1 \pm 1.3$ to $95.8 \pm 0.1 \%$, as shown in Fig. 8a, indicating most algal biomass produced in this semi-continuous cultivation was successfully harvested. The biomass productivity of $0.1 \mathrm{~mol} \mathrm{~L}^{-1}$ bicarbonate was from 0.14 to $0.24 \mathrm{~g} \mathrm{~L}^{-1} \mathrm{day}^{-1}$ for the recycling culture and that of the control was from 0.13 to $0.26 \mathrm{~g} \mathrm{~L}^{-1}$ day $^{-1}$ (Fig. 8b). Compared with this, higher biomass productivity was found in the $0.3 \mathrm{~mol} \mathrm{~L}^{-1}$ culture, where biomass productivity in the recycling culture was from 0.15 to $0.39 \mathrm{~g} \mathrm{~L}^{-1} \mathrm{day}^{-1}$, and that of the control culture was from 0.22 to $0.39 \mathrm{~g} \mathrm{~L}^{-1}$ day $^{-1}$.

The carbon utilization efficiency was also measured. As shown in Fig. 8c, the carbon utilization efficiency was higher than $100 \%$ for both $0.1 \mathrm{~mol} \mathrm{~L}^{-1}$ cultures from the 1st day, and the highest carbon utilization efficiencies of $242 \pm 3.1$ and $266 \pm 11 \%$ were achieved in the recycling and control culture, respectively. Different from this, the highest carbon utilization efficiency was $98 \pm 0.78 \%$ in the recycling culture with $0.3 \mathrm{~mol} \mathrm{~L}^{-1}$ bicarbonate and $87 \pm 3.6 \%$ in the control culture. The $\mathrm{pH}$ in both cultures with $0.1 \mathrm{~mol} \mathrm{~L}^{-1}$ bicarbonate exceeded the $\mathrm{pH}^{*}$ from the 1st day (Fig. 7b), and $\mathrm{CO}_{2}$ was transferred to the medium from the air. This should be the reason why they resulted in very high carbon utilization efficiency. 


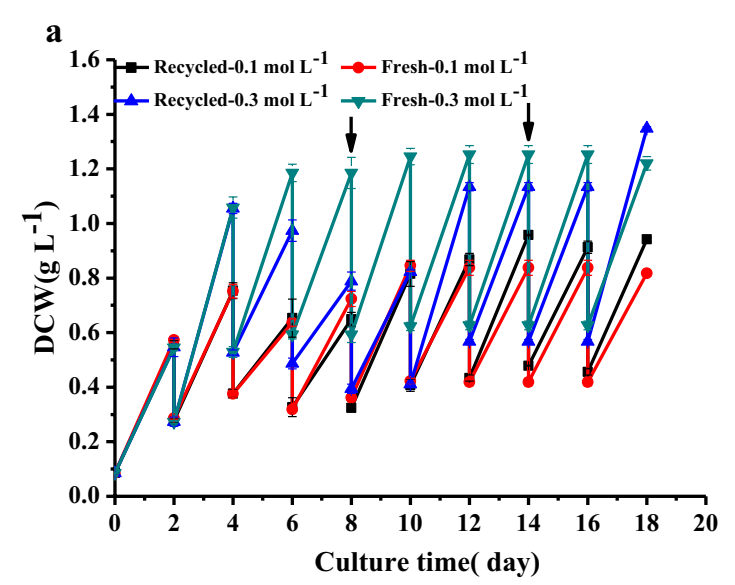

b

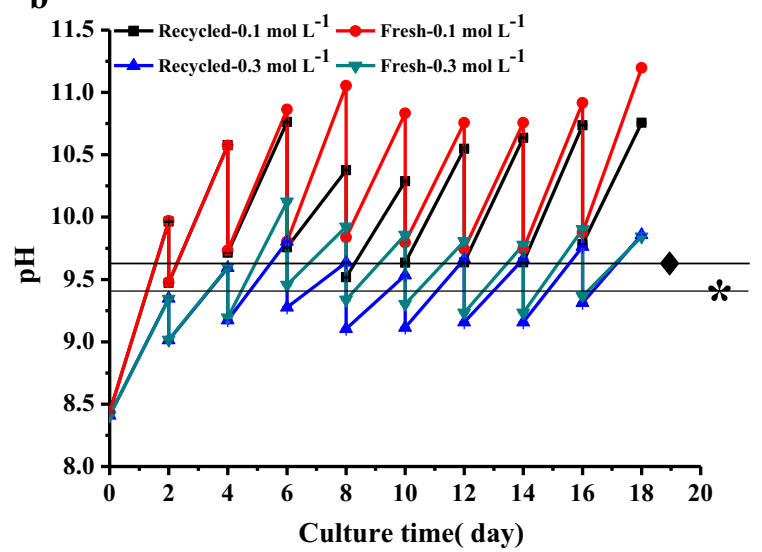

Fig. 7 A recycling culture of Neochloris oleoabundans with semi-continuous mode. a Biomass concentration, $\mathbf{b}$ pH change (spent medium bubbled $\mathrm{CO}_{2}$ to adjust $\mathrm{pH}$ and supply carbon). Arrows mean that the nutrients were added to the recycling culture at the 8th and 14th day, while the lines with asterisk and rhombus represents the $\mathrm{pH}^{*}$ of 0.1 and $0.3 \mathrm{~mol} \mathrm{~L}^{-1}$ bicarbonate, respectively. Values are the mean \pm SD of three independent measurements

\section{Discussion}

In this study, $N$. oleoabundans was selected for semi-continuous recycling culture with BICCAPS, and this was the first proof of the recyclability of a BICCAPS. This allows a close-loop carbon capture and algal cultivation process in which sodium bicarbonate was used for microalgal culture and spent medium with a high $\mathrm{pH}$ and enriched carbonate was used to absorb $\mathrm{CO}_{2}$ for the recycling culture. Fifty percent of this culture was harvested every 2 days and the biomass productivity of the recycling culture was at the same level as the control culture, which is replaced with fresh medium. In addition, compared to normal BICCAPS without recycling, the BICCAPS with recycling can significantly decrease water usage and reuse the dissolved nutrients [28]. Auto-flocculation or calcium assisted flocculation was used for harvesting of the produced biomass, which can save the cost of expensive flocculants and avoid biomass contamination. Thus, the process developed in this study would simultaneously reduce the cost of carbon capture, salt nutrients, water, algal cultivation, and harvesting.

A higher concentration of bicarbonate is preferred for a BICCAPS, since it not only has a stronger $\mathrm{pH}$ buffering effect, as shown above, but also makes the $\mathrm{CO}_{2}$ absorption process more efficient and supplies more inorganic carbon at the beginning of each culture [27]. A lower sodium bicarbonate concentration of $0.15 \mathrm{~mol} \mathrm{~L}^{-1}$ was used in a previous study on the culture of $N$. oleoabundans $[17,29]$. To obtain a strain that is tolerant to a high concentration of bicarbonate, the $N$. oleoabundans strain used in this study experienced an adapting process lasting for approximately 6 months. Before this adaption, it had optimal growth rate with $0.08 \mathrm{~mol} \mathrm{~L}^{-1}$ bicarbonate (data not shown). This indicates that an algal strains' tolerance for a high concentration of bicarbonate may be improved by an adaption process. More alkalihalophilic strains may be obtained with this method and used in BICCAPS.

A culture with a higher bicarbonate concentration resulted in a lower carbon utilizing efficiency (Fig. 4), since it has higher $\mathrm{pH}^{*} . \mathrm{CO}_{2}$ is transferred from the air into the culture only when the culture $\mathrm{pH}$ is higher than $\mathrm{pH}^{*}$. Thus, the $\mathrm{pH}$ should be controlled at a higher level $\left(>\mathrm{pH}^{*}\right)$ to achieve high carbon utilizing efficiency. In this study, the highest carbon utilization efficiency was up to $266 \pm 11 \%$ in the control culture with $0.1 \mathrm{~mol} \mathrm{~L}^{-1}$ bicarbonate at semi-continuous mode. This is much higher than that of $91.4 \%$ in cultivation with bicarbonate at a low $\mathrm{pH}$ [30] and $85.6 \%$ in cultivation with $15 \% \mathrm{CO}_{2}$ [31]. However, the high $\mathrm{pH}$ has a negative effect on microalgal growth. Thus, it is necessary to balance between the carbon utilization rate and the high $\mathrm{pH}$ 's detrimental effect. Microalgal strains tolerant to high $\mathrm{pH}$ are more favorable for a BICCAPS [27]. In this system, the mass transfer coefficient of $\mathrm{CO}_{2}\left(\mathrm{k}_{\mathrm{L}} \mathrm{a}_{\mathrm{CO}}\right)$ would affect carbon utilization efficiency [32] and this should be studied in the future.

In this study, the highest growth rate was achieved in a culture with a $0.3 \mathrm{~mol} \mathrm{~L}^{-1}$ bicarbonate concentration, but it had a carbon cost of three times that of $0.1 \mathrm{~mol} \mathrm{~L}^{-1}$ bicarbonate. However, it should be noted that this high concentration of bicarbonate was used in a recycling culture rather than used in only one batch, which means that the consumed carbon will be replenished by $\mathrm{CO}_{2}$ gas instead of bicarbonate. Thus, the real carbon cost was the used $\mathrm{CO}_{2}$ gas and it was affected by the carbon utilization efficiency. Additionally, the carbon utilization efficiency of the $0.3 \mathrm{~mol} \mathrm{~L}^{-1}$ culture was lower than the $0.1 \mathrm{~mol} \mathrm{~L}^{-1}$ culture (Fig. 8c), but a high carbon utilization 

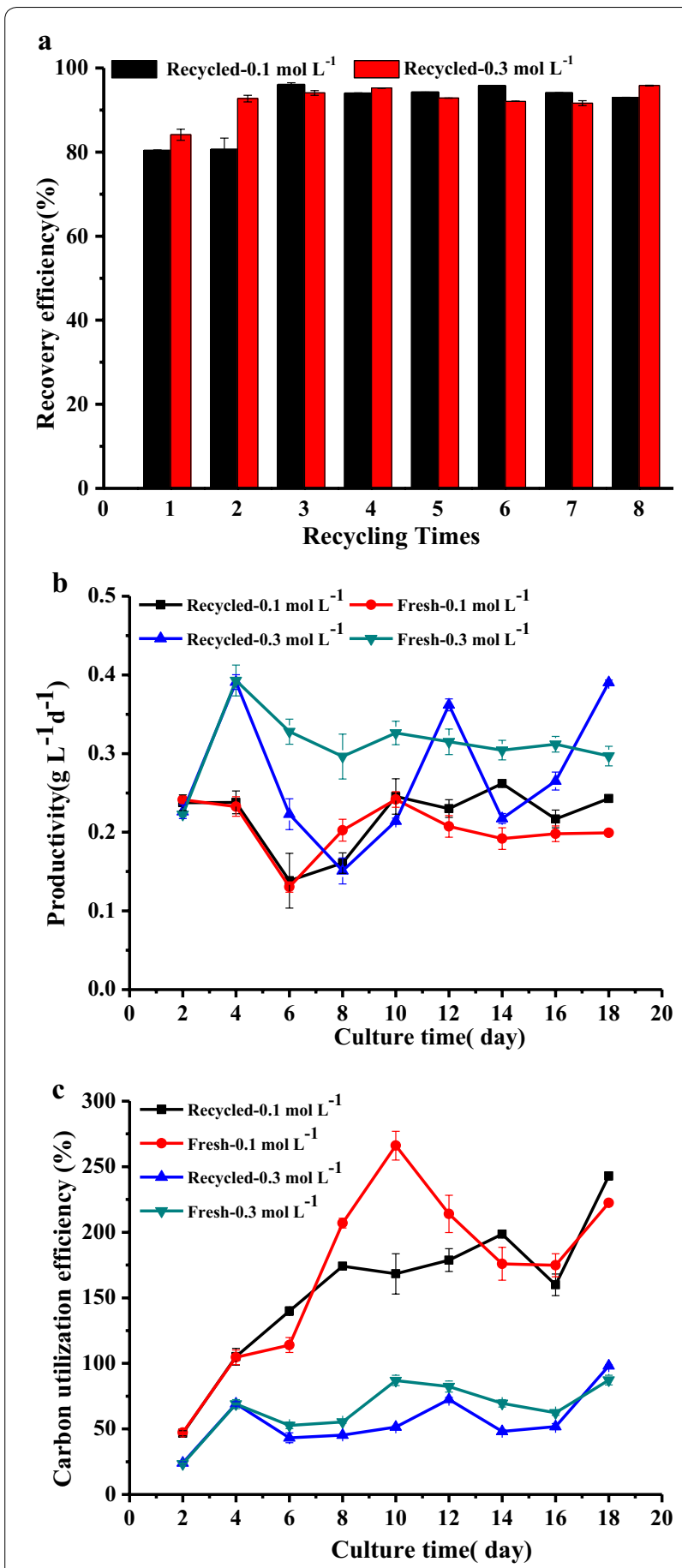

Fig. 8 a Auto-flocculation harvesting efficiency of N. oleoabundans; b daily biomass productivity and c carbon utilization efficiency during semi-continuous culture. Values are the mean \pm SD of three independent measurements

efficiency for $0.3 \mathrm{~mol} \mathrm{~L}^{-1}$ can be achieved by improving the culture $\mathrm{pH}$. In addition, it also produced the same high flocculation efficiency as the $0.1 \mathrm{~mol} \mathrm{~L}^{-1}$ cultures (Fig. 8a). According to these results, $0.3 \mathrm{~mol} \mathrm{~L}^{-1}$ should be optimal bicarbonate concentration for BICCAPS to produce $N$. oleoabundans biomass with low cost. This needs to be confirmed with a comprehensive life cycle and cost assessment [33], including a consideration of biomass productivity, carbon cost, flocculation efficiency and carbon utilization efficiency. This should be conducted in our future study.

One of the advantages of BICCAPS is that the high $\mathrm{pH}$ resulting from bicarbonate consumption may help in algal flocculation, and this feasibility was first proved in this study. High flocculation efficiency of algal biomass was achieved with a supplement of calcium (Fig. 4). In practice, calcium can be obtained from sea water, which has a much lower cost than other flocculants that are currently used [9]. However, calcium flocculation is challenged by reversible flocculation and the potential risk of a too high $\mathrm{Ca}^{2+}$ content in the harvested biomass [11]. Compared with this, auto-flocculation has no such problems, and it is ideal for a BICCAPS. In this study, it was found that bicarbonate concentration plays a significant role in flocculation efficiency. The highest flocculation efficiency of $92.8 \pm 3.4 \%$ was achieved in a culture with $0.7 \mathrm{~mol} \mathrm{~L}^{-1}$ bicarbonate at $\mathrm{pH}$ 9.7. The lowest flocculation efficiency of $12.8 \pm 2.7 \%$ was obtained in a culture with $0.1 \mathrm{~mol} \mathrm{~L}^{-1}$ bicarbonate at $\mathrm{pH} 10.9$. This is very different from results obtained in another study on alkaline flocculation, where higher flocculation efficiency is usually achieved in higher $\mathrm{pH}$. As far as this is concerned, it may be because extracellular polymeric substances were overproduced under the stressful conditions of higher bicarbonate concentration [34], which induces efficient flocculation efficiency. More details on this would be investigated in a future study.

It is notable that auto-flocculation in some cases in this study is time-consuming ( $24 \mathrm{~h}$ ) (Fig. 6). To make up for this disadvantage, semi-continuous recycling culture was used. In this mode, $2 / 3$ of the medium was in the culture system, and the other $1 / 3$ was in the recycling process, which includes flocculation, settling, and $\mathrm{CO}_{2}$ bubbling. This is also feasible in a massive-scale cultivation, since spent medium after biomass harvesting should be transported to the $\mathrm{CO}_{2}$ emission source to absorb more carbon and then re-transported back to the algal cultivation site. This process may take 1 or more days. However, this would not lead to a significantly higher harvesting cost, as long as enough storage tank or deep pond space is available. Additionally, a shorter harvesting time may be achieved by optimizing the $\mathrm{pH}$ and the initial concentration of bicarbonate (Fig. 6b), as well as the concentration of $\mathrm{Ca}^{2+}, \mathrm{Mg}^{2+}$, and $\mathrm{Fe}^{3+}[13,25]$.

Recycling spent medium plays an important role in reducing the algal production cost. This is even more important for a BICCAPS, but it may be limited by 
metabolic inhibitors accumulating in the spent medium $[35,36]$. However, no inhibition was observed in the whole recycling culture process of this study and it produced an even higher biomass concentration when compared with the control culture (Fig. 7a). Since no inhibition of $N$. oleoabundans growth occurred after recycling the medium so many times, inhibitor accumulation may either not occur at all or in concentrations too low to lead to inhibition. A similar phenomenon was observed in other studies, where no negative impact on the biomass growth rate or on cell quality in recycling cultures of Chlorella pyrenoidosa was observed [37]. A recent study also observed a positive effect in recycling of Chlorella vulgaris [38]. These results indicate that inhibitor accumulation and its influence is dependent on algal strains. Certainly, recycling culture is also threatened by impurities in $\mathrm{CO}_{2}$. For example, flue gas contains a large amount of $\mathrm{SO}_{\mathrm{x}}$ and $\mathrm{NO}_{\mathrm{x}}$, which may be converted into sulfate and nitrate if sodium carbonate is used to absorb $\mathrm{CO}_{2}$ in flue gas. In this situation, their effects to algal growth would require intensive studying in the future.

\section{Conclusions}

The feasibility of recycling culture with BICCAPS was proved, and the biomass concentration and productivity in the recycling culture are at the same level as the control culture with fresh medium. A high carbon utilization rate of up to $266 \pm 11 \%$ was obtained in fresh culture with $0.1 \mathrm{~mol} \mathrm{~L}^{-1}$ and $98 \pm 0.78 \%$ in $0.3 \mathrm{~mol} \mathrm{~L}^{-1}$ recycled culture. The produced algal biomass in recycling culture was harvested with alkaline flocculation without any flocculant. These results indicated that BICCAPS is not only promising to reduce the cost of carbon capture and algal cultivation but also the cost of harvesting.

\section{Authors' contributions}

CZ participated in the study design, performed the experiments and collected and analyzed the data. LC and RZ participated in the adaption of the strain. CZ and $Z C$ wrote and revised the manuscript. All authors read and approved the final manuscript.

\section{Acknowledgements}

The authors would like to thank He Zhu and Qiang Liu for their help in culture maintenance and sampling.

\section{Competing interests}

The authors declare that they have no competing interests.

\section{Availability of data and materials}

All data generated or analyzed during this study are included in this manuscript.

\section{Consent for publication}

All authors consent for publication.

Ethics approval and consent to participate Not applicable.

\section{Funding}

This work was funded by the "Fundamental Research Funds for the Central Universities" [DUT14RC(3)065].

\section{Publisher's Note}

Springer Nature remains neutral with regard to jurisdictional claims in published maps and institutional affiliations.

Received: 9 April 2018 Accepted: 6 July 2018

Published online: 24 July 2018

\section{References}

1. Williams PJLB, Laurens LML. Microalgae as biodiesel \& biomass feedstocks: Review \& analysis of the biochemistry, energetics \& economics. Energy Environ Sci. 2010;3:554-90.

2. Bajracharya S, et al. Biotransformation of carbon dioxide in bioelectrochemical systems: state of the art and future prospects. J Power Sources. 2017:356:256-73.

3. Hallenbeck PC, et al. Solar biofuels production with microalgae. Appl Energy. 2016:179:136-45.

4. Acien $\mathrm{FG}_{\text {, et }}$ al. Production cost of a real microalgae production plant and strategies to reduce it. Biotechnol Adv. 2012;30:1344-53.

5. Wang JK, Seibert M. Prospects for commercial production of diatoms. Biotechnol Biofuels. 2017:10:16.

6. Chi Z, O'Fallon JV, Chen S. Bicarbonate produced from carbon capture for algae culture. Trends Biotechnol. 2011;29:537-41.

7. Chi Z, et al. Bicarbonate-based integrated carbon capture and algae production system with alkalihalophilic cyanobacterium. Bioresour Technol. 2013;133:513-21.

8. Zhu C, Zhu H, Cheng L, Chi Z. Bicarbonate-based carbon capture and algal production system on ocean with floating inflatable membrane photobioreactor. J Appl Phycol. 2017;30(2):875-85.

9. Grima EM, et al. Recovery of microalgal biomass and metabolites: process options and economics. Biotechnol Adv. 2003;20:491-515.

10. Mathimani T, Mallick N. A comprehensive review on harvesting of microalgae for biodiesel — key challenges and future directions. Renew Sustain Energy Rev. 2018;91:1103-20.

11. Vandamme $D$, et al. Reversible flocculation of microalgae using magnesium hydroxide. Bioenergy Res. 2015;8:716-25.

12. Yoo C, et al. Simple processes for optimized growth and harvest of Ettlia $\mathrm{sp}$. by $\mathrm{pH}$ control using $\mathrm{CO}_{2}$ and light irradiation. Biotechnol Bioeng. 2015;112:288-96.

13. Vandamme D, et al. Alkaline flocculation of Phaeodactylum tricornutum induced by brucite and calcite. Bioresour Technol. 2015;196:656-61.

14. Smith BT, Davis RH. Sedimentation of algae flocculated using naturallyavailable, magnesium-based flocculants. Algal Res. 2012;1:32-9.

15. Vandamme $\mathrm{D}$, et al. Flocculation of Chlorella vulgaris induced by high $\mathrm{pH}$ : role of magnesium and calcium and practical implications. Bioresour Technol. 2012;105:114-9.

16. Choi YY, et al. Development of large-scale and economic pH control system for outdoor cultivation of microalgae Haematococcus pluvialis using industrial flue gas. Bioresour Technol. 2017;244:1235-44.

17. Santos AM, et al. Growth of oil accumulating microalga Neoch/oris oleoabundans under alkaline-saline conditions. Bioresour Technol. 2012;104:593-9.

18. Pruvost J, et al. Investigation of biomass and lipids production with Neochloris oleoabundans in photobioreactor. Bioresour Technol. 2009;100:5988-95.

19. Tornabene TG, et al. Lipid composition of the nitrogen starved green alga Neochloris oleoabundans. Enzyme Microb Technol. 1983;5:435-40.

20. Zavarzin GA, Zhilina TN, Kevbrin W. The alkaliphilic microbial community and its functional diversity. Microbiology. 1999;68:503-21.

21. Zhu CJ, Lee YK. Determination of biomass dry weight of marine microalgae. J Appl Phycol. 1997:9:189-94.

22. Wolf-Gladrow DA, et al. Total alkalinity: the explicit conservative expression and its application to biogeochemical processes. Mar Chem. 2007; 106:287-300. 
23. Da RG, et al. Chemical absorption and $\mathrm{CO}_{2}$ biofixation via the cultivation of Spirulina in semicontinuous mode with nutrient recycle. Bioresour Technol. 2015;192:321-7.

24. Millero FJ, et al. Dissociation constants of carbonic acid in seawater as a function of salinity and temperature. Mar Chem. 2006;100:80-94.

25. Beuckels A, et al. Influence of organic matter on flocculation of Chlorella vulgaris by calcium phosphate precipitation. Biomass Bioenergy. 2013;54:107-14

26. García-Pérez JS, et al. Influence of magnesium concentration, biomass concentration and $\mathrm{pH}$ on flocculation of Chlorella vulgaris. Algal Res. 2014;3:24-9.

27. Chi Z, et al. Selection of microalgae and cyanobacteria strains for bicarbonate-based integrated carbon capture and algae production system. Appl Biochem Biotechnol. 2014;172:447-57.

28. Wijffels RH, Barbosa MJ. An outlook on microalgal biofuels. Science. 2010;329:796-9.

29. Santos AM, et al. Biomass and lipid productivity of Neochloris oleoabundans under alkaline-saline conditions. Algal Res. 2013;2:204-11.

30. Kim GY, et al. Bicarbonate-based cultivation of Dunaliella salina for enhancing carbon utilization efficiency. Bioresour Technol. 2017;237:72-7.
31. Cheng J, et al. Improving CO2 fixation efficiency by optimizing Chlorella PY-ZU1 culture conditions in sequential bioreactors. Bioresour Technol. 2013:144:321-7.

32. Gao X, Kong B, Vigil RD. Characteristic time scales of mixing, mass transfer and biomass growth in a Taylor vortex algal photobioreactor. Bioresour Technol. 2015;198:283-91.

33. Zaimes GG, Vikas K. Microalgal biomass production pathways: evaluation of life cycle environmental impacts. Biotechnol Biofuels. 2013;6:88.

34. González-Fernández C, Ballesteros M. Microalgae autoflocculation: an alternative to high-energy consuming harvesting methods. J Appl Phycol. 2013;25:991-9.

35. Zhang X, et al. Recycling Nannochloropsis oceanica culture media and growth inhibitors characterization. Algal Res. 2016;20:282-90.

36. Depraetere $\mathrm{O}$, et al. Influence of culture medium recycling on the performance of Arthrospira platensis cultures. Algal Res. 2015;10:48-54.

37. Leone DE. Growth of Chlorella pyrenoidosa in recycled medium. Appl Microbiol. 1963;11:427.

38. Faroog W, et al. Effect of harvesting methods on the reusability of water for cultivation of Chlorella vulgaris, its lipid productivity and biodiesel quality. Algal Res. 2015;8:1-7.
Ready to submit your research? Choose BMC and benefit from:

- fast, convenient online submission

- thorough peer review by experienced researchers in your field

- rapid publication on acceptance

- support for research data, including large and complex data types

- gold Open Access which fosters wider collaboration and increased citations

- maximum visibility for your research: over 100M website views per year

At BMC, research is always in progress.

Learn more biomedcentral.com/submissions 